\title{
Larvicidal Potency of Dioscorea sansibarensis Leaf Extract against Vector Mosquitoes: Anopheles gambiae s.s. and Culex quinquefasciatus
}

\author{
Anitha Philbert \\ Department of Zoology and Wildlife Conservation, University of Dar es Salaam P. O. Box 35054, \\ Dar es Salaam, Tanzania \\ E-mail:annybyabato@yahoo.com; philbert.anitha@udsm.ac.tz \\ Received 1 Feb 2021, Revised 28 Apr 2021, Accepted 30 Apr 2021, Published May 2021
}

DOI: https://dx.doi.org/10.4314/tjs.v47i2.21

\begin{abstract}
Mosquitoes are responsible for transmission of illnesses of public health importance including malaria, lymphatic filariasis, dengue, chikungunya, and many other diseases caused by viruses. Vector control using synthetic insecticides has been the cornerstone for management of vectorborne diseases. However, the chemical based interventions have not been sustainable due to emergency of resistance against insecticides among disease vectors. Plant based mosquitocidal products can be potential alternative tools in vector control. Therefore, the present study aimed at exploring the larvicidal properties of Dioscorea sansibarensis leaf extract against malaria and lymphatic filariasis vectors; Anopheles gambiae s.s. and Culex quinquefasciatus. The larvicidal activities of Dioscorea sansibarensis were assessed following WHO test procedures. Ethanol leaf extract of Dioscorea sansibarensis was evaluated against all the four instar larvae stages of $A n$. gambiae s.s and $C x$. quinquefasciatus susceptible laboratory colonies. The highest larvicidal potency was shown against the $4^{\text {th }}$ instar stages of both species with the $\mathrm{LC}_{50}$ values of $60.915 \mathrm{ppm}$ and $80.700 \mathrm{ppm}$ for $C x$. quinquefasciatus and An. gambiae s.s., respectively. The respective $\mathrm{LC}_{95}$ values for Cx. quinquefasciatus and An. gambiae s.s. were $168.898 \mathrm{ppm}$ and $249.295 \mathrm{ppm}$. This implies that the extract can be applied as mosquito larvicide should its impact on non-targeted species be established.
\end{abstract}

Keywords: Dioscorea sansibarensis; vectors, mosquitoes, Zanzibar yams, Dar es Salaam, Tanzania.

\section{Introduction}

Mosquitoes transmit a variety of wellknown vector-borne diseases, including malaria, filariasis, encephalitis, yellow fever, chikungunya, dengue and many other arboviral infections, causing mortalities and morbidities across the globe. Vector-borne diseases constitute over $17 \%$ of all infectious diseases, causing more than 700,000 deaths annually (WHO 2020a). Malaria alone caused approximately 229 million cases and 400,000 deaths in 2019, and the highest burden was recorded from WHO-African region which accounted $94 \%$ of all the cases (WHO 2020a, 2020b). Mosquitoes in the Anopheles genera are responsible for transmission of malaria parasites, Anopheles gambie s.l. being the main vector in Tanzania. Culex quinquefasciatus on the other hand, transmits Wuchereria bancrofti responsible for lymphatic filariasis. Lymphatic filariasis is the second most common vectorborne parasitic disease after malaria accounting to 120 million global cases annually (Jones et al. 2018). In Tanzania, the burden of malaria remains high with 14-18 million new cases and approximately 120,000 deaths reported each 
year (Makundi et al. 2007). Vector control plays a central role in the prevention of malaria and other vector-borne diseases. The main vector control methods involve synthetic chemicals in form of Indoor Residual Sprays (IRS), Insecticide Treated Nets (ITNs)/Long Lasting Insecticidal Nets (LLINs) and larvicides. The past decade saw a significant decrease in incidences of vector-borne diseases as a result of massive scale up of the chemical based interventions (IRS and ITNS/LLINs) (Ashley et al. 2018, WHO 2020b). Malaria cases for example, decreased from 238 million in the year 2000 to 218 million cases in 2015 , nevertheless, recent records suggest rebound of the disease (Khatib et al. 2018, WHO 2020b). Despite the massive scale up of ITNs/LLINs and IRS, the sustainability of these interventions is faced by several challenges, including: vector resistance to insecticides, change in vector feeding and biting behavior, outdoor malaria transmission and adaptation of mosquito to polluted environments (Killeen et al. 2016, Antonio-Nkondjio et al. 2018). Early biting of An. gambiae s.s. between 18:00 21:00 hours has been reported, this occurs when people are not under protection of ITNs/LLINs (Githeko et al. 1996, Wamae et al. 2015, Sougoufara et al. 2020). Similary, early biting of $C x$. quinquefasciatus was recorded in the coastal region of Nigeria where a good number of females were trapped between 18001900 hours (Uttah et al. 2013). It was further reported that the circadian biting peak of $C x$. quinquefasciatus was between 18.00 and 20.00 hours outdoors (Uttah et al. 2013), and this means that vectors are less likely to be controlled by the current interventions (LLINs/IRS) that target vectors indoors. The increasing trend of vector resistance to insecticides used in LLINs and IRS (Ranson et al. 2011, Nardini et al. 2012, Antonio-Nkondjio et al. 2018, Sougoufara et al. 2020), the environmental issues and toxicity of the chemical based insecticides that spill over to the food chain, and their impacts on nontargeted species (Sharma et al. 2016), have led to exploration of environmentally friendly, non-persistent and species specific plant products which are locally available.

In that regard, researchers have transformed their interests towards the development and uses of botanical products for controlling mosquitoes and other insects which are considered safe and environmentally friendly alternatives (Isman 2000). Phytochemical products have a long history of uses and proven evidence of efficacy as antimicrobial, antioxidants, anti-inflamatory, insecticidal, and repellants (Obidiegwu et al. 2020). Furthermore, several studies have explored and established the efficacy of botanical extracts and essential oils for vector control (Kalimuthu et al. 2012, Kweka et al. 2008, Kovendan et al. 2013). Nevertheless, the potential of Dioscorea sansibarensis, the commonly used plant by farmers against crop pests, to control mosquito vectors has not been explored.

The plant (Dioscorea sansibarensis), also known as Zanzibar yam, is native to Tanzania and one of the largest and most widely distributed species of the genus Dioscorea L. in the coastal zones. It is the climber which produces both bulbils and underground tubers. The tubers/yams of various Dioscorea spp are used for food in many countries, with therapeutic values (Obidiegwu et al. 2020), other species have been characterized as toxic. Dioscorea sansibarensis vegetative parts are evergreen with broad leaves but always undamaged by chewing insects; the destructive herbivores also avoid feeding on them (Mauti et al. 2019). Although the potential of Dioscorea sansibarensis to control crop pests has been reported (Price et al. 2016, Kumar et al. 2017, Mauti et al. 2019), information concerning the usefulness and promising uses of the plant against disease vectors is lacking. Owing to the increasing level of vector resistance against synthetic insecticides (Antonio-Nkondjio et al. 2018), it is fundamental to explore the plant based natural products that would complement the existing vector control interventions. Therefore, this study explored the larvicidal potency of Dioscorea sansibarensis crude extract against 
the two vector species for possible screening of anti-mosquito agents.

\section{Materials and Methods \\ Collection of plant materials}

The leaves of the plant Dioscorea sansibarensis were collected from the small forest behind the Zoology-Botany buildings, Mwalimu Nyerere Campus, University of Dar es Salaam, Tanzania in June, 2020. One bucket of the leaves was collected by hand picking, the plant leaves were authenticated by a taxonomist from the Department of Botany, University of Dar es Salaam, where the voucher specimen (FMM 3910b) is deposited.

\section{Extract preparation}

The leaves of Dioscorea sansibarensis were washed with distilled water, and air dried under shade for seven days. The air-dried materials were powdered, and $1 \mathrm{~kg}$ powdered plant material was soaked in $3.0 \mathrm{~L}$ of ethanol for 24 hours then filtered by using cotton wool to obtain the filtrates. The filtrates were re-soaked for another 24 hours and taken to a rotary evaporator at $300 \mathrm{rpm}$ for vaporization of ethanol, the remnant was the crude extract. The crude extract was stored in a refrigerator at 4 ${ }^{\circ} \mathrm{C}$ ready for larvicidal bioassays. Plant extract preparation was executed by modifying the published procedure (Kovendan et al. 2013, Mauti et al. 2019). A stock solution (1\%) was prepared by diluting $200 \mathrm{mg}$ of extract with 20 $\mathrm{ml}$ ethanol. From this stock solution various concentrations were prepared for subsequent larvae bioassays, low concentrations of extract were tried to establish the lethal dose, and for this reason the concentrations were converted to ppm by using the formula $1 \mathrm{mg} / \mathrm{L}=1 \mathrm{ppm}$. The experiments for preparation of plant extracts were carried out at the Institute of Traditional Medicine of the National Institute for Medical Research, Tanzania.

\section{Larvae rearing}

The susceptible laboratory larvae were used for this study. The larvae were obtained from the Ifakara Health Institute (Bagamoyo branch) where the susceptible colonies are maintained. The first larvae instars of both An. gambie s.s. and $C x$. quinquefasciatus were collected, fed on tetramine fish food and maintained at $27{ }^{\circ} \mathrm{C}$ and $70 \%$ relative humidity (Philbert and Ijumba 2013, Philbert et al. 2017). All the four larvae instar stages were involved in assessments of plant extract pontency.

\section{Larvae bioassays}

The larvicidal potency of Dioscorea sansibarensis leaf extract was assessed at the following concentrations: $25 \mathrm{ppm}, 50 \mathrm{ppm}, 75$ ppm, 100 ppm, 200 ppm, 300 ppm and 400 ppm for all the four instar stages of both $A n$. gambie s.s. and Cx. quinquefasciatus. Mosquito larvae were separated in batches of 20. Each batch was transferred into a $250 \mathrm{ml}$ beaker containing a corresponding volume of water and a stock solution. Each bioassay had four replicates carried out concurrently at the same conditions and a control which contained water and ethanol as a solvent to make corresponding test volumes $(100 \mathrm{ml})$. The procedure was repeated for each extract concentration (25 ppm, $50 \mathrm{ppm}, 75 \mathrm{ppm}, 100$ ppm, 200 ppm, 300 ppm and 400 ppm), and for all the four larvae instar stages (I-IV) for both species. The dead larvae were recorded 24 hours after exposure. The larvae were touched gently using a plastic pipette and were considered dead in the absence of any signs of movement. Bioassay experiments were conducted following the WHO test procedure (WHO 2013).

\section{Data analysis}

The mean larvae mortality rate were computed and subjected to probit analysis for calculating the lethal concentrations at $50 \%$ and $95 \%\left(\mathrm{LC}_{50}\right.$ $\left.\& \mathrm{LC}_{95}\right)$ and other statistics at $95 \%$ fiducial values of upper confidence limit (UCL) and lower confidence limit (LCL) values, and paired sample t-test was computed to establish differences in mortality values between $A n$. gambie s.s. and $C x$. quinquefasciatus larvae. 


\section{Results}

The assessment of larvicidal potential of Dioscorea sansibarensis leaf extract by ethanol solvent carried out against the four instar stages of An. gambiae s.s. and Cx. quinquefasciatus are presented in Figures 1 and 2. The mortality rates are directly proportional to the concentrations of the extract across the four larvae instar stages of both species. Complete larval mortality (100\%) occurred at the highest concentrations between 300 and 400 ppm, and the lowest mortality $(2.5 \%$ and $12.5 \%)$ occurred at the lowest concentrations (25 and $50 \mathrm{ppm})$ for $A n$. gambie s.s. and $C x$. quinquefasciatus, respectively.

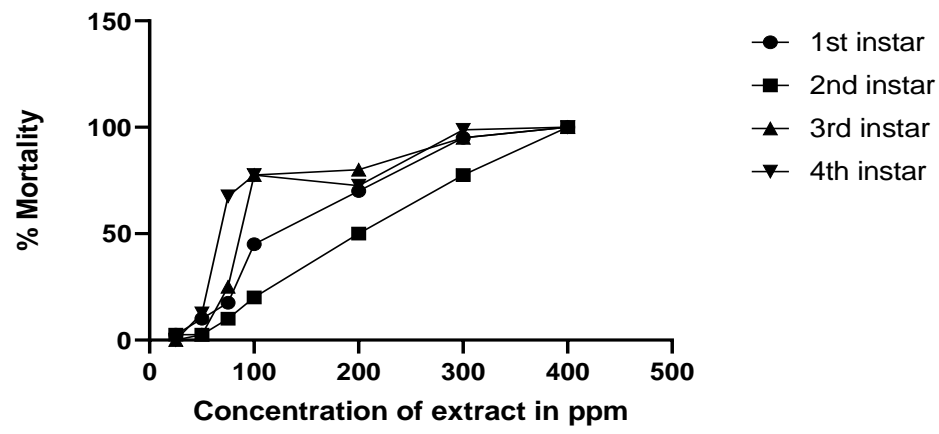

Figure 1: Percentage mortality of different larvae stages of An. gambiae s.s. against various concentration of Dioscorea sansibarensis leaf extracts.

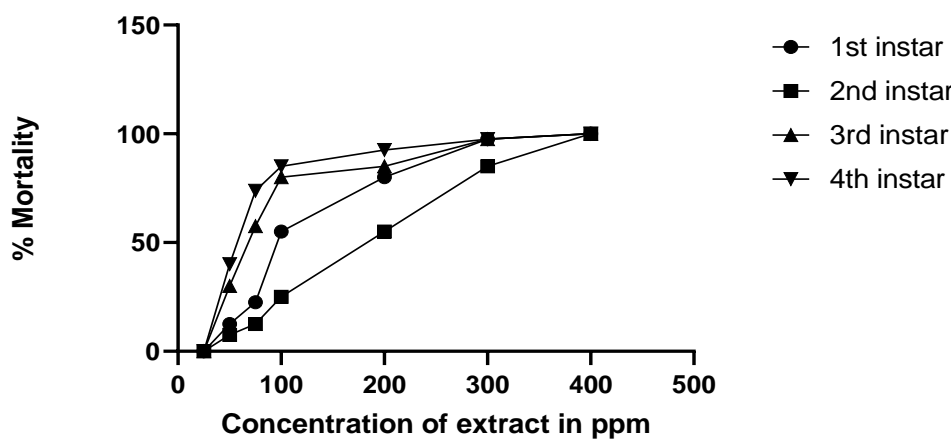

Figure 2: Percentage mortality of different larvae stages of $C x$. quinquefasciatus against various concentrations of Dioscorea sansibarensis leaf extracts.

The results showed that 24 hours exposure of the larvae could result in $100 \%$ mortality, irrespective of the developmental stage (Table 1). The control groups did not result in any larvae mortality after 24 hours. The lethal concentration to cause $50 \%$ mortality of the larvae ranged from 50.879 to 167.529 ppm for Cx. quinquefasciatus and 66.290 to 215.795 ppm for An. gambie s.s. with higher values recorded against second instar stages of both species. The lethal concentration of $95 \%$ larvae mortality was within the fiducial range values of 134.580-526.518 ppm and 249.295$919.045 \mathrm{ppm}$ for Cx. quinquefasciatus and An. gambie s.s., respectively. The study revealed the highest larvicidal potency of the extract against the $4^{\text {th }}$ instar stages for both species with the mean concentrations of $\mathrm{LC}_{50}$ of $80.700 \mathrm{ppm}$ and $60.915 \mathrm{ppm}$ for An. gambie s.s. and $C x$. quinquefasciatus, respectively (Table 2). 
Tanz. J. Sci. Vol. 47(2), 2021

Table 1: Percentage mortality of different larvae stages of An. gambiae s.s. and $C x$. quinquefasciatus mosquitoes exposed to various concentrations of Dioscorea sansibarensis ethanolic leaf extract

\begin{tabular}{|c|c|c|c|c|}
\hline $\begin{array}{l}\text { Larvae } \\
\text { stage }\end{array}$ & $\begin{array}{l}\text { Concentrations in } \\
\text { ppm }\end{array}$ & $\begin{array}{l}\text { An. gambiae s.s. } \\
\% \text { mortality } \pm \mathrm{SD}^{\mathrm{a}}\end{array}$ & $\begin{array}{l}\text { Cx. quinquefasciatus } \\
\% \text { mortality }+\mathrm{SD}^{\mathrm{a}}\end{array}$ & $P$-value \\
\hline \multirow{8}{*}{$\begin{array}{l}1^{\text {st }} \text { instar } \\
\text { larvae }\end{array}$} & 25 & $2.5 \pm 5$ & 0.0 & \multirow{8}{*}{0.0175} \\
\hline & 50 & $10 \pm 5$ & $12.5 \pm 0$ & \\
\hline & 75 & $17.5 \pm 0$ & $22.5 \pm 5$ & \\
\hline & 100 & $45 \pm 5$ & $55 \pm 5$ & \\
\hline & 200 & $70 \pm 19.15$ & $80 \pm 5.77$ & \\
\hline & 300 & $95 \pm 8.16$ & $97.5 \pm 8.16$ & \\
\hline & 400 & $100 \pm 5.16$ & $100 \pm 5$ & \\
\hline & Control & $0 \pm 0$ & $0 \pm 0$ & \\
\hline \multirow{8}{*}{$\begin{array}{l}2^{\text {nd }} \text { instar } \\
\text { larvae }\end{array}$} & 25 & $2.5 \pm 5$ & $0 \pm 0$ & \multirow{8}{*}{$0.0488^{*}$} \\
\hline & 50 & $2.5 \pm 5$ & $7.5 \pm 5$ & \\
\hline & 75 & $10 \pm 8.16$ & $12.5 \pm 9.57$ & \\
\hline & 100 & $20 \pm 0$ & $25 \pm 5.77$ & \\
\hline & 200 & $50 \pm 8.16$ & $55 \pm 5.77$ & \\
\hline & 300 & $77.5 \pm 5$ & $85 \pm 5.77$ & \\
\hline & 400 & $100 \pm 0$ & $100 \pm 0$ & \\
\hline & Control & $0 \pm 0$ & $0 \pm 0$ & \\
\hline \multirow{8}{*}{$\begin{array}{l}3^{\text {rd }} \text { instar } \\
\text { larvae }\end{array}$} & 25 & $0 \pm 0$ & $0 \pm 0$ & \multirow{8}{*}{0.1046} \\
\hline & 50 & $2.5 \pm 5$ & $30 \pm 8.16$ & \\
\hline & 75 & $25 \pm 5.77$ & $57.5 \pm 9.57$ & \\
\hline & 100 & $77.5 \pm 5$ & $80 \pm 0$ & \\
\hline & 200 & $80 \pm 8.16$ & $85 \pm 5.77$ & \\
\hline & 300 & $95 \pm 5.77$ & $97.5 \pm 5$ & \\
\hline & 400 & $100 \pm 0$ & $100 \pm 0$ & \\
\hline & Control & $0 \pm 0$ & $0 \pm 0$ & \\
\hline \multirow{8}{*}{$\begin{array}{l}4^{\text {th }} \text { instar } \\
\text { larvae }\end{array}$} & 25 & $0 \pm 0$ & $0 \pm 0$ & \multirow{8}{*}{0.0871} \\
\hline & 50 & $12.5 \pm 5$ & $40 \pm 14.14$ & \\
\hline & 75 & $67.5 \pm 9.57$ & $73.8 \pm 4.78$ & \\
\hline & 100 & $77.5 \pm 5$ & $85 \pm 5.77$ & \\
\hline & 200 & $72.5 \pm 13.3$ & $92.5 \pm 5$ & \\
\hline & 300 & $98.8 \pm 2.5$ & $97.5 \pm 5$ & \\
\hline & 400 & $100 \pm 0$ & $100 \pm 0$ & \\
\hline & Control & $0 \pm 0$ & $0 \pm 0$ & \\
\hline
\end{tabular}

$*$ = significant at $95 \% \mathrm{CI}$; paired sample $\mathrm{t}-\mathrm{test} ; \mathrm{SD}^{\mathrm{a}}=$ standard deviation for the mean of 4 replicates. The overall interaction was significant $(\mathrm{p}=0.0011)$, with significantly higher mortality in Cx. quinquefasciatus than An. gambiae s.s. two-tailed t $=3.658, \mathrm{df}=28$. 
Table 2: Larvicidal potential of the leaf ethanol extract of Dioscorea sansibariensis against the four instar stages An. gambiae s.s. and Cx. quinquefasciatus after 24 hours exposure time

\begin{tabular}{lllllll}
\hline Mosquito species & $\begin{array}{l}\text { Instar } \\
\text { stage }\end{array}$ & $\begin{array}{l}\mathrm{LC}_{50} \\
(\mathrm{ppm})\end{array}$ & $\begin{array}{l}95 \% \\
\text { limits }\end{array}$ & Fiducial & $\begin{array}{l}\mathrm{LC}_{95} \\
(\mathrm{ppm})\end{array}$ & $\begin{array}{l}95 \% \\
\text { limits }\end{array}$ \\
\hline An. gambiae s.s & 1 & 118.363 & $104.111-134.725$ & 343.186 & $279.084-456.422$ \\
& 2 & 169.659 & $135.839-215.795$ & 500.129 & $355.494-919.045$ \\
& 3 & 101.229 & $88.630-115.268$ & 254.135 & $208.677-337.740$ \\
Cx. quinquefasciatus & 4 & 80.700 & $66.290-96.391$ & 249.295 & $191.017-380.607$ \\
& 1 & 105.099 & $96.493-114.478$ & 273.140 & $237.194-326.528$ \\
& 2 & 152.944 & $139.888-167.529$ & 433.374 & $371.365-526.518$ \\
& 3 & 72.653 & $65.759-79.808$ & 218.095 & $187.299-265.042$ \\
& 4 & 60.915 & $50.879-71.150$ & 168.898 & $134.580-240.931$ \\
\hline
\end{tabular}

\section{Discussion}

The crude ethanol extract of Dioscorea sansibariensis has a significant larvicidal potency against the two important vector mosquitoes $C x$. quinquefasciatus, and $A n$. gambiae s.s. In the present study, the larvicidal effects of the plant extract against the four instar larvae stages varied according to the concentrations used. The larvae mortality increased with increasing concentrations and the maximum mortality $(100 \%)$ was attained between 300 and 400 ppm extract concentrations for both species. The $\mathrm{LC}_{50}$ values ranged from 60.915 to $152.944 \mathrm{ppm}$ for Cx. quinquefasciatus and 80.700 to 169.659 ppm for An. gambiae s.s. The highest larvicidal activities were observed for the $4^{\text {th }}$ instar stages of both species. These results are comparable to other previous studies (Sakthivadivel and Daniel 2008, Bagavan et al. 2009). The assessment of the toxicity of six medicinal plant extracts, Acacia nilotica, Jatropha Cxrcas, Citrullus colocynthis, Withania somnifera (leaves), A. mexicana (leaves and seeds) also resulted in an $\mathrm{LC}_{50}$ value of less than $100 \mathrm{ppm}$ against $3^{\text {rd }}$ instars of $C x$. quinquefasciatus, An. stephensi, and $A e$. aegypti (Sakthivadivel and Daniel 2008). Similary, the leaf extracts of the plants Citrus sinensis, Ocimum canum, Rhinacanthus nasutus and Ocimum sanctum when tested against larvae of Anopheles subpictus and Culex tritaeniorhynchus gave the $\mathrm{LC}_{50}$ values ranging between $21.6-88.15 \mathrm{ppm}$ and 39.32 109.12 ppm, respectively (Bagavan et al.
2009). Similar findings were also reported when the larvicidal activity of ethanol Cadaba indica lam leaf extract was investigated against Ae. aegypti which gave the $\mathrm{LC}_{50}$ value of 143.75 ppm (Kalimuthu et al. 2012).

Several studies have shown that plants are sources of bioactive compounds that can be used to develop environmentally safe antivector and anti-pest agents which are cheap and user friendly. The screening of local medicinal plants for mosquitocidal agents from plants have been attempted in many countries some decades ago (Crobsy 1971, Berenbaum 1985). Nevertheless, the applications of these products for vector control at field operation level are limited. The scale up of synthetic insecticides in terms of ITNs and IRS led to decreased malaria cases in most malarious countries (O’Meara et al. 2010, Ashley et al. 2018), but recent reports suggest the disease resurgence (WHO 2020b). This increase is attributed to vector resistance to insecticides, parasite resistance to anti-malaria drugs as well as change of vector behavior with more species now biting earlier before bed time. Early biting of both malaria and lymphatic filariasis vectors have been reported from many countries (Githeko et al. 1996, Uttah et al. 2013, Wamae et al. 2015, Killeen et al. 2016, Sherrard-Smith et al. 2019), thus the need for new vector control alternatives to complement the existing ones is now pertinent than ever.

The control of diseases vectors has been responsible for shrinking the map of many vector-borne diseases, and the need for the 
integrated vector control methods (IVM) using both insecticides and non-insecticide based methods is emphasized (Wilson et al. 2020). The overreliance on the chemical based interventions that replaced the traditional methods such as environmental management, habitat modification/manipulation making them unsuitable for larvae development has proved abortive. Moreover, several attempts to screen medicinal plants for antimosquito products including ovicides, larvicides, adulticides and repellants have not been scaled up for possible applications in the fields. Many studies are laboratory based and the findings remain of academic interests. The Dioscorea sansibarensis leaf extract showed potency against all the four instar larvae stages of the main vector species investigated. These are preliminary findings that need to be further investigated to characterize the phytochemical compounds and functional groups to establish the impacts of the product against other untargeted species for possible scale up. This calls for increased investment in vector control interventions that will utilize indigenous knowledge and local products other than synthetic chemicals.

\section{Conclusion}

The findings of this study clearly showed the larvicidal efficiency of Dioscorea sansibarensis against An. gambiae s.s. and $C x$. quinquefasciatus vector mosquitoes. Although the safety of the product to humans and other untargeted species remains unknown, the plant is suitable candidate for development of mosquitocidal product. Extensive studies on this plant against other mosquito stages (eggs, pupa and adults), its repellency properties, longevity, bioactive compounds and their modes of action are required.

\section{Acknowledgements}

This work was made possible by the generous support of the Consortium for Advanced Research Training in Africa (CARTA) through its postdoctoral fellowship award. CARTA is jointly led by the African Population and
Health Research Center and the University of the Witwatersrand and funded by the Carnegie Corporation of New York (Grant No. G-1654067), Sida (Grant No: 54100113), the DELTAS Africa Initiative (Grant No: 107768/Z/15/Z). The DELTAS Africa Initiative is an independent funding scheme of the African Academy of Sciences (AAS)'s Alliance for Accelerating Excellence in Science in Africa (AESA) and supported by the New Partnership for Africa's Development Planning and Coordinating Agency (NEPAD Agency) with funding from the Wellcome Trust (UK) and the UK government. The laboratory technicians of the Institute of Traditional Medicine, National Institute for Medical Research are thanked for assistance in extract preparation. Ms Rose Philipo of the Ifakara Health Institute is thanked for provision of the mosquito larvae. The statements made and views expressed are solely the responsibility of the author.

\section{Declaration of interest}

The author declares no competing interests.

\section{References}

Antonio-Nkondjio C, Sandjo NN, AwonoAmbene P and Wondji SC 2018 Implementing a larviciding efficacy or effectiveness control intervention against malaria vectors: key parameters for success. Parasit. Vectors 11: 57.

Ashley EA, Phyo AP and Woodrow CJ 2018 Malaria. Lancet 391: 1608-1621.

Bagavan A, Kamaraj C, Rahuman AA, Elango G, Zahir AA and Pandiyan G 2009 Evaluation of larvicidal and nymphicidal potential of plant extracts against Anopheles subpictus Grassi, Culex tritaeniorhynchus Giles and Aphis gossypii Glover. Parasitol. Res. 104(5): 1109-1117.

Berenbaum MR 1985 Brementoun revisited: allochemical interactions among in plants. Recent Adv. Phytochem. 19: 139-169.

Crobsy DG 1971 Minor insecticides of plant origin. Naturally occurring insecticides. In 
Jacobson M (Ed.) (pp. 171-239). New York: Marcel Dekker.

Githeko AK, Adungo NI, Karanja DM, Hawley WA, Vulule JM, Seroney IK, Ofulla AVO, Atieli FK, Ondijo SO, Genga IO, Odada PK, Situbi PA and Oloo JA 1996 Some observations on the biting behavior of Anopheles gambiae s.s., Anopheles arabiensis, and Anopheles funestus and their implications for malaria control. Exp. Parasitol. 82: 306-315.

Isman MB 2000 Plant essential oils for pest and disease management. Crop Protection 19(8-10): 603-608.

Jones C, Ngasala B, Derua YA, Tarimo D, Reimer L, Bockarie M and Malecela MN 2018 Lymphatic filariasis transmission in Rufiji District, southeastern Tanzania: infection status of the human population and mosquito vectors after twelve rounds of mass drug administration. Parasit. Vectors 11: 588

Kalimuthu K, Murugan K, Panneerselvam C and Hwang JS 2012 Mosquito larvicidal activity of Cadaba indica lam leaf extracts against the dengue vector, Aedes aegypti. Asian J. Plant Sci. Res. 2(5): 633-637.

Khatib AR, Chaki PP, Wang DQ, Mlacha PY, Mihayo MG, Gavana T, Xiao N, Zhou XN and Abdullah S 2018 Epidemiological characterization of malaria in rural southern Tanzania following China-Tanzania pilot joint malaria control baseline survey. Malar. J. 17(292).

Killeen GF, Govella NJ, Lwetoijera DW and Okumu FO 2016 Most outdoor malaria transmission by behaviourally-resistant Anopheles arabiensis is mediated by mosquitoes that have previously been inside houses. Malar. J. 15(225).

Kovendan K, Murugan K, Kumar PM, Thiyagarajan P and William SJ 2013 Ovicidal, repellent, adulticidal and field evaluations of plant extract against dengue, malaria and filarial vectors. Parasitol. Res. 112: 1205-1219.

Kumar S, Das G, Shin HS and Patra JK 2017 Dioscorea spp. (a wild edible tuber): a study on its ethnopharmacological potential and traditional use by the local people of Similipal Biosphere Reserve, India. Front. Pharmacol. 8: 52.

Kweka EJ, Mosha F, Lowassa A, Mahande AM, Kitau J, Matowo J, Mahande MJ, Massenga CP, Tenu F, Feston E, Lyatuu EE, Mboya MA, Mndeme R, Chuwa G and Temu EA 2008 Ethnobotanical study of some of mosquito repellent plants in northeastern Tanzania. Malar. J. 7(152).

Makundi EA, Mboera LGE, Hamisi M. Malebo HM and Kitua AY 2007 Priority setting on malaria interventions in Tanzania: strategies and challenges to mitigate against the intolerable burden. Am. J. Trop. Med. Hyg. 77(6): 106-111.

Mauti GO, Kasigwa PK, Munissi JJE and Onguso JM 2019 Evaluation of the repellent effect of Dioscorea sansibarensis Pax (Dioscoreaceae) leaf essential oil against Bruchus chinensis Linnaeus, 1758 (Coleoptera: Bruchidae). Polish J. Entomol. 88(2): 119-128.

Nardini L, Christian RN, Coetzer N, Ranson H, Coetzee M and Koekemoer LL 2012 Detoxification enzymes associated with insecticide resistance in laboratory strains of Anopheles arabiensis of different geographic origin. Parasit. Vectors 5(113).

O'Meara WP, Mangeni JN, Steketee R and Greenwood B 2010 Changes in the burden of malaria in sub-Saharan Africa. Lancet Infect. Dis. 10: 545-555.

Obidiegwu JE, Lyons JB and Chilaka CA 2020 The Dioscorea genus (yam)-an appraisal of nutritional and therapeutic potentials. Foods 9(9): 1304.

Philbert A and Ijumba NJ 2013 Preferred breeding habitats of Aedes aegypti (DipteraCxlicidae) mosquito and its public health implications in Dar es Salaam, Tanzania. $J$. Environ. Res. Manage. 4(10): 344-351.

Philbert A, Lyantagaye SL, Pradel G, Ngwa CJ and Nkwengulila G 2017 Pyrethroids and DDT tolerance of Anopheles gambiae s.l. from Sengerema District, an area of intensive pesticide usage in north-western 
Tanzania. Trop. Med. Int. Health 22(4): 388-398.

Price EJ, Wilkin P, Sarasan V and Fraser PD 2016 Metabolite profiling of Dioscorea (yam) species reveals underutilised biodiversity and renewable sources for high-value compounds. Sci. Rep. 6(29136).

Ranson H, N'Guessan R, Lines J, Moiroux N, Nkuni Z and Corbel V 2011 Pyrethroid resistance in African anopheline mosquitoes: what are the implications for malaria control? Trends Parasitol. 27: 9198.

Sakthivadivel M and Daniel T 2008 Evaluation of certain insecticidal plants for the control of vector mosquitoes viz. Culex quinquefasciatus, Anopheles stephensi and Aedes aegypti. Appl. Entomol. Zool. 43(1): 57-63.

Sharma A, Kumar S and Tripathi P 2016 Evaluation of the larvicidal efficacy of five indigenous weeds against an Indian strain of dengue Vector, Aedes aegypti L. (Diptera: Cxlicidae). J. Parasitol. Res. 2016.

Sherrard-Smith E, Skarp JE, Beale AD, Fornadel C, Norris LC, Moore SJ, Mihreteabh S, Charlwoodi JD, Bhatta S, Winskilla P, Griffina JT and Churchera TS 2019 Mosquito feeding behavior and how it influences residual malaria transmission across Africa. Proc. Natl. Acad. Sci. 116(30): 15086-15095.
Sougoufara S, Ottih EC and Tripet F 2020 The need for new vector control approaches targeting outdoor biting anopheline malaria vector communities. Parasit. Vectors 13(295).

Uttah EC, Wokem GN and Okonofua C 2013 The abundance and biting patterns of Culex quinquefasciatus Say (Cxlicidae) in the Coastal region of Nigeria. Int. Scholarly Res. Notices 2013.

Wamae PM, Githeko AK, Otieno GO, Kabiru EW and Duombia SO 2015 Early biting of the Anopheles gambiae s.s. and its challenges to vector control using insecticide treated nets in western Kenya highlands. Acta Tropica 150: 136-142.

WHO 2013 Test procedures for insecticide resistance monitoring in malaria vector mosquitoes Geneva. Switzerland.

WHO 2020a Vector borne diseases. Retrieved from www.who.int/news-room/factsheets/detail/vector-borne-diseases website:

WHO 2020b World Malaria Report 2020. 20 Years of Global Progress and Challenges. Geneva. Switzerland.

Wilson AL, Courtenay O, Kelly-Hope LA, Scott TW, Takken W, Torr SJ and Lindsay SW 2020 The importance of vector control for the control and elimination of vectorborne diseases. PLoS Negl. Trop. Dis. 14(1): e0007831 